\title{
DA VIOLÊNCIA PARA A CULTURA DE PAZ NA ESCOLA: CONTRIBUIÇÕES DA PEDAGOGIA INSTITUCIONAL
}

\author{
FERNANDO CÉZAR BEZERRA DE ANDRADE \\ Doutor em Educação pela Universidade Federal da Paraíba. Professor do Programa de Pós-Graduação em Educação da \\ Universidade Federal da Paraíba. E-mail: frazec@uol.com.br \\ ANDRÉA PIRES DE OLIVEIRA \\ Mestranda no Programa de Pós-Graduação em Educação da Universidade Federal da Paraíba. \\ E-mail: andreapirespsicologia@gmail.com \\ KATHERINNE ROZY VIEIRA GONZAGA \\ Doutoranda no Programa de Pós-Graduação em Educação da Universidade Federal da Paraíba. \\ E-mail: katherinnegonzaga@hotmail.com
}

\begin{abstract}
RESUMO
Ensinar a conviver pacificamente é um grande desafio para docentes, pois os conflitos relacionais fazem parte da convivência humana. Situações que vão de indisciplina até as de violência, para serem pedagogicamente aproveitadas com aquele fim, requerem de docentes um manejo eficaz e corriqueiro na sala de aula e na escola. Este artigo apresenta a Pedagogia Institucional (PI) como alternativa para a gestão educadora de conflitos. Após breve apresentação teórica da PI, interpretamos uma situação de conflito relacional registrada há alguns anos durante projeto de extensão universitária que acompanha instituição de Educação Infantil na capital da Paraíba. Os dados foram extraídos de anotações de diário de campo e interpretados segundo a teoria winnicottiana. Os resultados mostram que a gestão dos conflitos relacionais na escola por meio da aplicação de leis e limites, instituídos a partir de dispositivos envolvendo lugares e o recurso à fala para resolver conflitos e estabelecer regras para o bem coletivo, favorece o crescimento emocional, a capacidade de cuidar dos outros e a aprendizagem de valores a isso vinculados, capacidades indissociáveis à construção de uma cultura de paz na escola.
\end{abstract}

Palavras-chave:Conflitos relacionais na escola. Intervenção docente. Pedagogia Institucional. Teoria Winnicottiana. Cultura de Paz.

\section{VIOLENCE FOR PEACE CULTURE AT SCHOOL: PEDAGOGY INSTITUTIONAL CONTRIBUTIONS}

\begin{abstract}
Teachingtolivepeacefullyis a major challenge for teachers, as long as relationalconflicts are partofhumansociety. In orderachievethatgoalfromexploringpedagogicalythoseconflicts (in a scalefrom indiscipline

teachersshouldmanageeffectivelydailysituationsatclassroomandschool.

ThisarticlepresentstheInstitutionalPedagogy (PI) as analternativetotheeducative management ofconflicts. After a brieftheoreticalpresentationof PI, weinterpret a conflictregistered in a childhoodeducationinstitution in the capital ofParaiba a fewyearsago, duringthedevelopmentofanextensionproject. Data wereextractedfromfielddiary notes andinterpretedaccordingtoWinnicott'stheory. The results show thatthe management ofrelationalconflictsatschool (byapplyinginstitutionallawsandlimits, withthe help ofpracticesinvolvingtheperfectioningof social roles andthe use of speech to solve conflictsandestablishrules for thecollectiveinterest) favorstheemotionalgrowth, thecapacitytocare for otherpeople. Also, it enhanceslearningaboutprosocialvalues, inextricablylinkedtothecapacitybuildingof a cultureofpeaceatschool.
\end{abstract}


Keywords:Relationalconflictsatschool. Management ofconflictsbyteachers. Institucional Pedagogy.Winnicott'stheory. Cultureof Peace.

\section{Introdução}

Nos tempos de hoje,quando a globalização afeta os modos de ensinar e aprender, novas exigências são feitas ao campo educativo (JIMÉNEZ, 2007). Nesse contexto, quatro pilares pensados para uma educação global - aprender a conhecer, aprender a fazer, aprender a viver juntos e aprender a ser - visam transpor uma educação instrumental, com vistas a instituir uma educação que articule formação técnica e pessoal do sujeito (DELORS, 2006; GALLO, 2000).

Isso é especialmente importante quando se pensa que padrões de convívio estão em mutação, inclusive na escola. $O$ que era antes nela naturalizado ou nem chegava a ser percebido torna-se um problema pedagógico, como é o caso dos conflitos relacionais. No intuito de identificar e caracterizar esses fenômenos, pesquisadores relatam seus altos índices, num espectro que vai desde a indisciplina até violências de diversas naturezas - contra a pessoa, seus bens ou o patrimônio da própria escola. (ABRAMOVAY, 2004; ABRAMOVAY; RUA, 2002; DEBARBIEUX; BLAYA, 2002).

Concebemos as situações de conflitos relacionais como aquelas nas quais se encontram, concomitantemente, oposição de ideias, comportamentos, valores e interesses. Essas, quando não são manejadas adequadamente, geram tensões e obstáculos nas relações pedagógicas (ANDRADE, 2007).

Nesse contexto, aprender a viver juntos (intrinsecamente articulado aos outros quatro pilares) é um grande desafio, uma vez que os conflitos relacionais fazem parte da convivência humana e, nela, das relações intersubjetivas. Saber conviver supõe a construção da capacidade de “compreensão do outro e [...] percepção das interdependências [...] no respeito pelos valores do pluralismo, da compreensão mútua e da paz" (DELORS, 2006, p. 102). Concorre, portanto, para a constituição de uma cultura de paz, mas, naturalmente, presume o processo educativo que faça coextensivas a convivência e a paz.

A Educação para a Paz é um 'processo pelo qual se promovem conhecimentos, habilidades, atitudes e valores necessários para induzir mudanças de comportamento que possibilitam às crianças, aos jovens e aos adultos a prevenir a violência (tanto em sua manifestação direta, como em sua forma estrutural); resolver conflitos de forma pacífica e criar condições que conduzam à paz (na sua dimensão intrapessoal; interpessoal; ambiental; intergrupal; nacional e/ou internacional)' (DISKIN; ROIZMAN, 2002, p. 11). 
Ora, entendemos que a educação para a paz requer o desenvolvimento da capacidade de se preocupar com o outro e, consequentemente, de sentir e aceitar responsabilidade pelo resultado das situações vivenciadas, descrita por Winnicott (2005). Nesse processo, a responsabilidade de instituir a paz transforma-se em valor pessoal, intrinsecamente associado às personalidades.

Assim, fica óbvio não ser suficiente a mera constituição formal de regras e critérios para a formação da cultura de paz na escola. É preciso mudar práticas, que não se dobram ao discurso facilmente, já que constituem hábitos e dispositivos de poder arraigados em posições subjetivas modos segundo os quais cada sujeito da escola age em suas relações interpessoais. A posição subjetiva pode favorecer (ou dificultar) a construção de uma cultura de paz.

É na gestão dos conflitos relacionais que a compreensão sobre a posição subjetiva do(a) educador(a) mostra-se ainda mais relevante, pois esses profissionais, com o poder de marcar o desenvolvimento cognitivo, emocional e social dos discentes (ANDRADE, 2007; MARCHESI, 2008; PAIN, 2009; WINNICOTT, 2008), precisam mudar suas posições subjetivas em situações geradoras de tensão para a convivência na escola.

Para tanto, uma formação que prepare para intervir competentemente nas relações interpessoais dentro da escola mostra-se mais valiosa, num cenário em que, de modo geral, os educadores ainda não são preparados para gerir conflitos relacionais.

Vê-se, com isso, que também as subjetividades estão em jogo. Um olhar mais atento aos processos microscópicos que se dão nas subjetividades e na intersubjetividade é indispensável. Um caminho viável para reconhecer, acompanhar e mesmo interferir nesse nível de comunicação e convivência é oferecido pela Pedagogia Institucional (PI), uma abordagem capaz de contribuir solidamente para uma cultura de paz na escola (PAIN, 2009).

Este artigo defende a importância do manejo educacional eficiente de situações de conflitos relacionais na escola com apoio na teoria e nas práticas da PI, para a construção de uma cultura de paz. Neste trabalho, enfocamos a teoria da PI como uma das lentes com que interpretamos uma situação empírica, argumentando que conceitos propostos por essa Pedagogia auxiliam a compreender o desenvolvimento da capacidade de participar em uma vida cidadã, desde os primeiros anos de escolarização - com a instituição de lugares (papéis e funções para a participação de cada pessoa), a adoção de leis e limites organizadores das atividades e poderes pedagógicos, e da linguagem, tudo isso pelo uso de técnicas e métodos de trabalho chamados de dispositivos.

Para ilustrar esse conjunto de afirmações, após uma breve apresentação da PI, fazemos a análise interpretativa de uma situação de conflito relacional real, registrada pela segunda autora 
deste artigo, durante sua participação, por sete anos, num projeto de extensão universitária que acompanha uma instituição de Educação Infantil na capital da Paraíba.

Cabe esclarecer que o relato desse material empírico foi retirado de anotações de diário de campo e que ele é analisado por meio de interpretação apoiada na teoria psicanalítica - ainda que, diferentemente de grande parte das interpretações desenvolvidas por autores vinculados à PI (vinculados à psicanálise lacaniana), utilizemos a psicanálise winnicottiana.

A interpretação é feita tomando-se como premissa sua relação com a transferência ${ }^{1}$ ocorrida em meio escolar. De acordo com Winnicott (1983, p. 146), “a interpretação relaciona o fenômeno específico da transferência a uma parcela da realidade psíquica do paciente, e isso significa em alguns casos relacioná-lo ao mesmo tempo a uma parcela da vida passada do paciente". Nesse sentido, pressupomos que, nas relações escolares, repitam-se, com novo formato (em razão do tipo de enquadre), padrões afetivos que se estabelecem antes e fora da escola (geralmente, com os familiares ou adultos responsáveis pela criança).

Sabemos dos limites de interpretação da transferência fora do contexto clínico: sua extensão e profundidade, bem como sua função são diferentes, tanto no que dizem respeito aos processos envolvidos quanto ao tipo de produção oportunizado. Não obstante, admitindo que o inconsciente manifeste-se em ambas as atividades (clínica e educacional), sustentamos o uso da interpretação para além dos muros da clínica.

A partir disso, pretende-se demonstrar em que medida a teoria e prática da PI contribui, através do manejo eficaz de situações de conflitos relacionais na escola, para a construção de uma cultura de paz. Para tanto, inicialmente, caracterizamos a PI em sua teoria e técnicas para, na segunda parte do artigo, apresentarmos o método da coleta de dados empíricos, relativos ao acompanhamento de uma menina de cinco anos, que são apresentados e interpretados na seção seguinte. Concluímos nosso texto com uma breve remissão dessas análises a uma cultura de paz.

\section{A Pedagogia Institucional: um subsídio teórico para pensar e agir em conflitos na escola}

A tarefa de analisar e intervir no manejo de situações de conflitos relacionais na escola exige um suporte teórico que considere e valorize o aspecto subjetivo das relações interpessoais, presente na interação professor - aluno, aluno-aluno, gestor-professor etc. Nas palavras de Andrade (2007, p.

\footnotetext{
${ }^{1}$ Transferência é “o processo pelo qual os desejos inconscientes se atualizam sobre determinados objetos no quadro de um certo tipo de relação estabelecida com eles e, eminentemente, no quadro da relação analítica." (LAPLANCHE; PONTALIS, 1995, p.514). Para Winnicott (2000) o destaque está nas formas clínicas de transferência. Quanto mais imaturo o ego, mais importante é o contexto ambiental proporcionado ao paciente, ou seja, o contexto é mais importante que a interpretação e à medida que o ego vai amadurecendo a ênfase vai sendo transferida de um aspecto para outro.
} 
95): "educar é cuidar das condições que instituem e mantêm as relações intersubjetivas em torno do conhecimento - inclusive o que nelas há de conflito, tensão e violência”. Julgamos que a Pedagogia Institucional (PI) oferece uma abordagem consistente para isso, cuja teoria explica a constituição de um espaço de construção de conhecimento não apenas formal, mas, também, interrelacional.

Nascida em 1958 do seio das experiências de Fernand Oury (professor) no Movimento Freinet, na França, a PI concebe o ser humano como agente das leis e regras nas instituições reguladoras da sociedade. "Instituição" é definida com duplo significado: diz respeito às estratégias utilizadas para organizar habitualmente a vida escolar; e concerne, também, ao princípio que orienta essas estratégias - o do bem coletivo como critério regulador das ações individuais. Nesta última acepção, o termo aproxima-se tanto do imperativo para obedecer a regras de comunicação e negociação (acordos), quanto da recusa do que se oponha aos acordos ou os impeça (a violência).

Por conseguinte, cabe aprender a exprimir sentimentos e desejos em palavras e gestos organizados por técnicas de expressão e de trabalho em grupo, que também favorecem a autorregulação e a cooperação em grupo (PAIN, 2009).Isso se dá em aulas-passeio; na imprensa escolar (usada para registrar as produções textuais criadas após os passeios); na livre expressão de pensamento do alunado (estimulando a autonomia do aluno e o trabalho coletivo); e na correspondência interescolar (cuja função era valorizar a escrita para a criança, revelando uma de suas funções) - dispositivos freinetianos (SAMPAIO, 2007), também empregados na PI. A ideia freinetiana da sala de aula cooperativa - em que alunos e professores têm autonomia de pensamento e de opinião - consolida a PI (PAIN, 2009).

Logo, a PI é um "conjunto de técnicas, de dispositivos, de instrumentos, de instituições aperfeiçoadas" (HEVÉLINE; ROBBES, 2000, p. 11) pela valorização do grupo como unidade mínima para as interações e pela interpretação dos processos grupais e individuais (intersubjetividade e subjetividade) com a teoria psicanalítica (geralmente o pensamento de Lacan). "Ela coloca adultos e crianças dentro de situações novas e diversificadas, que exigem de cada um engajamento pessoal, iniciativa, ação, continuidade" (HEVÉLINE; ROBBES, 2000, p. 15).

As técnicas viabilizam apoderar-se do instrumento de produção concreto, do controle do produto e da participação na organização social da produção, tanto por parte de quem aprende quanto de quem ensina. Os grupos favorecem o surgimento de jogos de identificação individualizando o aluno que ele tem de particular e agrupando-o no que tem de comum com o outro. E o inconsciente, por ser valorizado, permite ao aluno existir de modo autônomo na sala de aula (HÉVELINE; ROBBES, 2009). 
Nessa classe cooperativa, Oury propôs que em sala de aula fosse possível falar para resolver conflitos (HEVÉLINE; ROBBES, 2000). Essa prática é muito importante, uma vez que, para a PI, “os lugares de fala são [...] uma solução para tratar os problemas de violência e para ajudar os/as alunos/as em sua aprendizagem da cidadania" (HÉVELINE; ROBBES, 2009, p. 65). As regras para falar e as leis que as fundamentam estruturam as relações interpessoais na sala de aula e na escola, são condicionantes de "instauração da troca (no sentido simbólico), da palavra, do acesso à linguagem (interdito). A lei permite, libera e abre possibilidades no jogo escolar e pedagógico." (HÉVELINE; ROBBES, 2009, p. 33).

Para demarcar o espaço e representá-lo como campo de aquisição de conhecimentos através do desejo do alunado, a PI propõe a instauração de quatro fundamentos: leis, lugar, limites e linguagem. Além disso, a PI se utiliza como dispositivos para uma educação ativa, pautada na contenção da violência, na resolução dos conflitos relacionais e na formação para uma vida cidadã: da turma institucionalizada, dos lugares de fala e da formação continuada de professores (ANDRADE; CARVALHO, 2009).

As leis são os acordos fundadores, as regras básicas inegociáveis, que materializam os limites e servem de parâmetros a serem respeitados nas relações interpessoais. Elas permitem o desenvolvimento da sociedade e o progresso do indivíduo nas suas relações sociais e não podem ser questionadas nem pelo professor e nem pelo aluno. São três as leis básicas que norteiam as relações intersubjetivas na escola: trabalhar para sobreviver (a obrigação de aprender e construir coletivamente), interditar a violência (a obrigação da verbalização) e interditar o incesto (a impossibilidade de uma relação privilegiada entre crianças e adultos). Elas estruturam o jogo escolar e pedagógico, fazendo do espaço educacional um meio para a expressão dos desejos daqueles que dele participam (HEVÉLINE; ROBBES, 2009).

O lugar diz tanto do espaço real como, também, do espaço simbólico. Refere-se ao papel de cada um e suas funções nas relações com o coletivo e no individual. O lugar favorece distinguir-se diante do outro e do grupo, poder reconhecer-se diferente do outro, dizer "eu" entre os outros (HEVÉLINE; ROBBES, 2009). É ter a capacidade de tomar posse de si, de responsabilizar-se por seus atos e de se colocar diante do outro para reivindicar algo que lhe é de direito.

Os limites são as regras negociadas coletivamente. Limites também são leis negociadas em conjunto e que vão se desenrolando ao tempo em que situações de dificuldades e necessidades são encontradas. Além disso, colaboram também na conscientização do lugar de cada um, demarcando esses lugares, o que auxilia na diferenciação, no caso da escola, entre professores e alunos (HEVÉLINE; ROBBES, 2009). 
A linguagem perpassa todo e qualquer princípio, aspecto central da PI por ser meio de expressão do desejo - esse importante motor das ações, segundo a psicanálise. "O desejo encontra na linguagem uma via privilegiada de expressão e regulação, pois a linguagem é feita do dito, do interdito e do entredito" (ANDRADE, 2007, p.97). O uso da palavra compensa o sujeito em função dos limites impostos pela realidade interna e externa, tendo em vista que a linguagem proporciona a autonomia, criatividade e as sublimações - colaborando para a tolerância dos limites, pois evita a passagem de impulsos agressivos ao ato e reduz a probabilidade de ataques destrutivos.Ter alguém no ambiente que perceba, acolha e valorize o que é dito pelo aluno, ou o que ele expressa, favorece o processo de maturação e a aquisição de maturidade - como defende Winnicott (2005), uma vez que faz emergir o sujeito, de modo que ele se compromete com o ambiente e consigo mesmo, desenvolvendo a capacidade de cuidar de si mesmo e do outro, adquirindo a capacidade de viver no social.

Dispositivos são instituídos pela PI para garantir que esses quatro fundamentos constituamse na relação pedagógica e nela sejam preservados. Eles servem de guia às regras de civilidade e às condutas individuais adequadas à convivência no coletivo. Alguns dos mais importantes são: a organização da turma, do tempo e do espaço físico da sala de aula, a formação de grupos de trabalho, a adoção do coletivo como destinatário desse trabalho e os lugares de fala.

A organização da turma e do espaço físico da sala de aula são aspectos importantes para o desenvolvimento de um bom trabalho na escola (HEVÉLINE; ROBBES, 2009). Para cada atividade deve-se prever a melhor e mais produtiva disposição no espaço, assim como organização de cronograma para o cumprimento da tarefa. A turma institucionalizada tem sua organização planejada de maneira que as instituições, os lugares e objetos disponíveis para o processo de ensino e de aprendizagem sejam claros e contínuos. Considerando a gestão do tempo, com precisão e respeito e os imprevistos como relevantes e discutidos em grupo, favorece-se o trabalho no coletivo. Rituais e palavras de ordem são gradativamente estabelecidos e constituem uma referência comum para o grupo, favorecendo a tomada de decisões e atitudes (HEVÉLINE; ROBBES, 2009).

A formação de grupos também é um dispositivo significativo para a instituição de uma turma e do trabalho. O trabalho em grupos favorece a individuação e também a identificação com o coletivo, articulando as dimensões: subjetiva, cognitiva, prática, social e didática, importantes para a formação global do aluno (ANDRADE; CARVALHO, 2009). Neste sentido, institucionalizar uma turma depende do enquadre ${ }^{2}$ e da organização de grupos específicos para cada objetivo.

\footnotetext{
${ }^{2}$ Para Zimerman e Osório (2001) o enquadre pode ser definido como a soma de todos os procedimentos que organizam, normatizam e possibilitam o funcionamento grupal, resultando em um conjunto de regras, atitudes e combinações que
} 
Os lugares de fala na PI são momentos que favorecem a expressão verbal de sentimentos, avaliações e fantasias de cada um, a fim de que todos aprendam a falar e a escutar em coletividade, aprendendo, sobretudo, o respeito à existência e a condição de sujeito de cada um, envolvido no processo de ensino e aprendizagem, servindo à garantia, mudança ou conservação do lugar subjetivo de cada um nesse processo.

Assim, faz-se necessário estruturar lugares de fala e isso se dá através da linguagem, das leis e dos limites, com o intuito de se produzir um lugar que possa ser habitado e favorecedor à palavra, excelência da mediação, do manejo adequado das situações de conflitos relacionais. Neste sentido, a atuação dos professores, escola - detentores das leis fundadoras da instituição - é imprescindível, assim como a condição destes para se comunicar e intervir adequadamente nas situações de conflitos relacionais. É por isso que a PI chama a atenção para a importância da formação ao professor:

A ideia de preparar docentes para o manejo de situações de conflitos relacionais, proposta pela PI, coaduna-se com a ideia de uma formação que considere o aprendizado uma experiência em constante movimento, não restrito aos bancos de uma instituição formal de ensino, mas que valorize também a vida pessoal do(a) professor(a), as situações por ele(a) vivenciadas durante a vida, permeadas, também, por seus inconscientes. A PI propõe uma formação docente continuada pautada em trocas de experiências, nos trabalhos em grupos, nos grupos de estudos e na análise das experiências bem-sucedidas e fracassadas (HEVÉLINE; ROBBES, 2009).

Ora, fica claro, nesse processo: dispositivos da PI ajudam a organizar os conflitos, mas não eliminam, por si mesmos, definitivamente, tensões, visto que ansiedade e, naturalmente, conflitos relacionais fazem parte inerente da convivência. A PI atua principalmente para resolvê-los, mas considera a violência uma possibilidade a ser permanentemente vigiada nas relações sociais, por conta da agressividade que, nas culturas, tende a ser legitimada como recurso para solucionar impasses (PAIN, 2006). Os assuntos conflitantes estarão sempre presentes, assim como as situações de conflitos relacionais, pois são, inclusive, ricas oportunidades para estruturar relações interpessoais nos tecidos intersubjetivos e subjetivos. "Talvez seja apenas num meio estruturado que cada indivíduo possa ele mesmo se construir, isto é, fazer a aprendizagem da diferença" (COLOMBIER; MANGEL; PERDRIAULT, 1989, p.61).

viabilizam o trabalho. Estes autores entendem que o enquadre engloba não apenas o espaço físico no qual os encontros acontecem, mas também os acordos prévios de horário, frequência, duração, além da própria composição do grupo e número médio de participantes. $\mathrm{O}$ enquadre é, portanto, um dos instrumentos que permite que um grupo se estruture. Não é um elemento fixo e inalterável estabelecido no início do trabalho, mas possui uma dimensão cambiável que provoca a leitura e a análise dos constantes movimentos latentes e manifestos por cada um dos membros do grupo. 
Desse modo, a gestão dos conflitos por educadores(as) e, em particular, docentes torna-se ainda mais relevante: quando não resolvidos pela negociação, eles influenciam e interrompem as atividades comuns e o desenvolvimento afetivo e intelectual dos adultos e crianças envolvidos. (HEVÉLINE; ROBBES, 2000). Devem ser manejados de forma a evitar o progresso às situações de violência, pois esta sim, não promove possibilidades de reparação dos vínculos inter-relacionais. Não se deve deixar de tratar de assuntos conflitantes com as pessoas envolvidas.

Uma situação de conflitos relacionais em escolas ajuda-nos a aplicar alguns desses conceitos, demonstrando como a PI pode orientar educadores e educadoras a manejarem melhor as tensões e violências no seu cotidiano. É o que faremos, ao apresentarmos o acompanhamento lúdico-terapêutico, pela segunda autora deste artigo, de uma criança de cinco anos, numa pequena creche da periferia da capital paraibana.

\section{Metodologia}

Esta investigação, caracterizada como uma pesquisa qualitativa, do tipo estudo de caso, ocorreu no contexto de um projeto de intervenção mais amplo, realizado em creche filantrópica, mantida numa periferia da capital paraibana, por doações de uma paróquia católica e por servidores do Poder Judiciário do Estado da Paraíba. Por sua vez, os funcionários da instituição eram cedidos através de um convênio com a Prefeitura Municipal.

Em termos infraestruturais, a creche funcionava numa pequena casa (originalmente, uma residência) sem planejamento específico para as funções próprias à Educação Infantil, de modo que os espaços eram estreitos e improvisados, contando com pequeno terraço (único lugar de brincadeiras livres), berçário, refeitório (que funcionava como sala para as crianças dos dois aos cinco anos), acolhendo cinco dias por semana, em média, sessenta crianças. Mesmo pequena, era bem asseada e organizada, atendendo-se a necessidades como alimentação, banho e dormida.

Havia uma desproporção entre o número de funcionários e o de crianças: eram nove, entre os quais quatro educadoras, para cuidar de 60 crianças cujas famílias eram socialmente vulneráveis (filhas de catadores de lixo, drogaditos, domésticas etc.) do entorno da creche. Além destas educadoras, uma cozinheira, dois auxiliares de serviços gerais e o diretor da creche completavam o quadro de profissionais. As crianças permaneciam todo o dia na instituição, com cinco refeições distribuídas com outras atividades rotineiras, ao longo de dez horas de permanência no local: banho matinal e vespertino, brincadeiras livres para crianças com mais de dois anos, uma hora de sono às tardes, tarefas com educadora e crianças (pintura, contação de histórias, desenhos etc.). Os cerca de 
20 bebês, em particular, ficavam por o dia no berçário, dormindo, assistindo a programas televisivos ou brincando (sob supervisão, mas sem participação direta das educadoras).

O projeto de intervenção dava-se em caráter de extensão universitária junto a educadoras, familiares e crianças - uma pesquisa-ação qualitativa, desenvolvida por uma equipe de intervenção composta por oito discentes de Psicologia e dois psicólogos voluntários, sob a supervisão de psicanalista, com vistas a desenvolver a escuta psicanalítica e intervenções que possibilitassem a promoção da saúde mental tanto das crianças quanto dos adultos envolvidos na instituição. Sua duração já transcorria ao longo de quatro anos quando se deu o acompanhamento lúdico-terapêutico da criança cujo estudo é aqui apresentado.

O estudo de caso utiliza-se de "uma realidade para confrontar dados, visando buscar explicações e fundamentos para os fenômenos que caracterizam o objeto de estudo" (OLIVEIRA, 2005, p. 62), permitindo que o fenômeno seja estudado através de variadas técnicas e métodos que facilitam a sua compreensão. Essa técnica, empregada com os princípios psicanalíticos, termina por enfocar as relações intersubjetivas que servem de cenário e de lastro tanto para entender a psicodinâmica do sujeito envolvido, e das relações mantidas por ele e a partir dele; quanto, de outro lado, para explicar seu acompanhamento por quem pesquisa dessa forma.

No ano em que se deu o acompanhamento do caso aqui apresentado, foram realizados 32 encontros de duas horas semanais com as crianças (totalizando 64 horas de acompanhamento); e, de forma intercalada, 16 encontros com o grupo de funcionários da creche e 16 encontros com familiares. para a escuta de educadores(as). Aqui se analisarão os dados encontrados, especialmente, com uma criança, filha de uma funcionária da creche, cuja identidade é aqui protegida pelo nome fictício Laura.

Laura, cujas observações foram registradas em diário de campo pela segunda autora deste artigo, foi observada por toda a creche, visto que transitava por todos os espaços da creche: ainda assim, os dados mais numerosos foram coletados na sala das crianças mais velhas (com dois a cinco anos, todas juntas no mesmo ambiente, pois à época não havia separação de turmas por idade após os dois anos).

Esse recinto, que também servia como refeitório, era ampla, contígua à cozinha e a uma pequena área de serviço. Não tinha janelas, sendo arejada por ventiladores; a iluminação era predominantemente artificial, mesmo que algumas telhas transparentes garantissem alguma luz natural no ambiente. Era preenchida por móveis de plástico (cadeiras) e madeira (mesas), um pequeno armário para guardar material pedagógico, colchonetes infantis e várias caixas de brinquedo. 
As observações forneceram material a respeito da relação estabelecida entre funcionários, educadoras e Laura: como os adultos se dirigiam a ela, como ela reagia frente ao movimento desses adultos, além de como as outras crianças se direcionavam a Laura e reagiam a ela.Para o registro das falas verbais e expressões faciais dos(as) participantes da pesquisa, utilizou-se um diário de campo. E os dados encontrados foram analisados através de interpretações dos movimentos psicodinâmicos com base na teoria psicanalítica de Donald Winnicott, realizando uma análise de uma situação de conflito relacional vivenciada, especialmente por Laura.

De todo modo, é pertinente esclarecer que as interpretações aqui apresentadas não tiveram sua validade verificada com os participantes dessa experiência, mas serviram de norte para a identificação e compreensão de seus movimentos subjetivos, durante as atividades do projeto de extensão, assim como, neste trabalho, para a demonstração das contribuições da PI para o manejo dos conflitos na escola, concorrendo para uma cultura de paz.

\section{Laura: um estudo de caso sobre a agressividade infantil como pedido de limites institucionais}

Uma das características da PI é oferecer um modelo de intervenção que valoriza o conflito e considera a violência um risco permanente nas relações pedagógicas. Ora, muitas das situações de violência explicam-se precisamente quando a agressividade não encontra o enquadre que a organiza: é o que entendemos ter havido na creche em que estava Laura.

Convém insistirmos que nem o projeto de intervenção (de que se extraiu o caso), nem a política pedagógica da creche foram organizadas segundo os paradigmas da PI: todavia, a análise aqui empreendida comunga com a Pedagogia Institucional no recurso à interpretação psicanalítica. Isso nos leva a reconhecer a possibilidade de pensar tal experiência à luz dos dispositivos e conceitos da PI, a fim de usá-la como ilustração.

Para tornar isso mais claro, é importante comentarmos um pouco sobre os processos relacionais em torno de Laura, que lhe serviam de ambiente, bem como aqueles que foram desenvolvidos pela equipe extensionista. Assim, no caso desta equipe, uma vez por semana, em atividades grupais, a equipe de intervenção, reafirmava os postulados psicanalíticos no que dizem respeito à presença do outro, real ou imaginário, na vida do ser humano: com as crianças, brincavase (com desenho, pintura, leitura de estórias, dramatização e jogos, brincadeiras espontâneas) a fim de mobilizar afetividade, promovendo a subjetivação infantil. Além disso, a cada quinzena, abria-se um espaço de escuta psicanalítica para dois grupos de adultos: os familiares, que traziam as dificuldades em relação à condução da educação dos filhos e acerca de sua relação com o cotidiano 
da creche. Na outra quinzena, os(as) educadores(as), expressavam as implicações subjetivas de seu trabalho, suas dificuldades no cuidar das crianças o que possibilitava buscarem juntos soluções para dificuldades. Por sua vez, a equipe de intervenção, sob supervisão de uma psicanalista, estudava e refletia semanalmente sobre os dados coletados e avaliava suas ações e impressões a fim de atentar para os modos com os quais pode haver interferência das subjetividades de seus integrantes na condução do projeto extensionista.

Com essa intervenção continuada de mais de meia década, muitas práticas foram modificadas incidindo na rotina da Creche e nas interações entre os adultos e as crianças. No início dessa extensão, a equipe identificou a ausência de atividades lúdicas, programadas ou espontâneas na rotina da creche; tampouco havia atenção para a subjetividade dos(as) educadores(as); na interação com as crianças, não havia enquadres- no sentido de limites organizadores das relações continentes e claros. Tudo isso, do ponto da PI, enfraquecia a presença das leis, dos lugares, dos limites e da linguagem (HEVÉLINE; ROBBES, 2009), contribuindo para a aparição de angústia, agressividade e, logo, conflitos nas interações dos diferentes subgrupos (adultos entre si, crianças entre si, adultos e crianças).

A equipe de intervenção passou, então, a propor um espaço para o brincar no qual buscavase para além do favorecimento do desenvolvimento psicomotor e social das crianças, o favorecimento de um ambiente no qual as crianças pudessem experimentar sua espontaneidade, de modo seguro, garantido pela presença dos adultos, representada pela equipe cuja função continente favorecia o desenvolvimento emocional infantil. A partir desses momentos de intervenção, foi possível sensibilizar os(as) educadores(as) sobre a importância do brincar como dispositivo relacional e pedagógico e como parte do desenvolvimento emocional saudável das crianças.

Nas reuniões com os(as) educadores(as) e os familiares das crianças desenvolveram um enquadre mínimo que deu suporte a um cotidiano mais organizado: as crianças foram dispostas em dois grupos, por faixa estaria, para brincarem livremente com acompanhamento por uma hora e meia. Elas, na brincadeira, assim como os adultos na fala, têm a liberdade para expressar-se pela fala (se já sabem falar), mas lhes são interditadas: a agressão física e verbal contra si ou outros componentes do grupo, e a destruição dos brinquedos (no caso das crianças) ou o rompimento da lei ou dos limites (no caso das crianças mais velhas e dos adultos). Todos e todas também participavam da arrumação da sala após as brincadeiras (se forem crianças, como forma de fechamento das atividades lúdicas) ou conservar o patrimônio da creche (se forem adultos).

Essas transformações são bem ilustradas pela história de Laura, cinco anos, filha de funcionários da creche, menina vivaz e esperta, porém agressiva e possessiva. Ela demonstrava 
alguma liderança: provavelmente, por ser afilhada do diretor da creche e ter seus pais trabalhando na instituição, sentia-se segura para dar evasão à sua raiva e à sua onipotência, sem maiores constrangimentos. Inicialmente, batia e mordia as outras crianças e, por vezes, os adultos (inclusive a professora), quando contrariada. Impunha suas próprias regras e sentia-se dona dos brinquedos, o que provocava conflitos e brigas com as crianças, além de birras e queixas ao padrinho se contrariada.

As crianças queixavam-se de Laura: "olha, ela tá batendo, tira ela daqui", "coloca ela de castigo, ela pegou meu brinquedo". Essas falas revelavam o desejo do grupo de que os comportamentos agressivos de Laura fossem barrados, mobilizando as crianças a pedirem punições contra a mesma. No entanto, ao menor sinal de interdição desses privilégios por parte dos(das) educadores(as) ou da equipe de intervenção, ela reagia com ataques de fúria, jogando o que tivesse a seu alcance nas pessoas ou jogando-se ela própria no chão, esperneando e chorando até que suas exigências fossem atendidas.

Quando se conseguia algum tipo de interdição, Laura regredia, pedia chupeta, falava como bebê, preferindo muitas vezes ficar no berçário, com a mãe (funcionária da creche), ao invés de ficar com as crianças de sua faixa etária, o que lhe era permitido. A conduta de Laura assinalava, nos tempos iniciais do projeto, que as instituições (leis e limites) eram frágeis: sem elas, Laura, ao invés de falar, agia impulsivamente sob o influxo de seus afetos.

Uma cena ilustra os tempos do começo da intervenção, quando ainda não havia enquadre: em dia de brincadeiras, também terapêuticas na medida em que mediadas pela equipe de intervenção, Laura estava especialmente agitada e controladora, não conseguia brincar com as outras crianças e passava todo o tempo tomando os brinquedos dos outros. Uma das estagiárias aproximou-se dela e lhe descreveu seu comportamento: disse perceber que Laura não estava conseguindo brincar, que só conseguia tomar os brinquedos. A estagiária ofereceu a alternativa de brincar interagindo com outras duas meninas e com as bonecas e panelinhas que Laura carregava em seus braços de um lado para outro da sala. A menina, então, gritou: "Padrinho!", provavelmente pedindo socorro, com medo de que seu lugar especial fosse ameaçado, diante daquela proposta. O diretor, ao ouvir os gritos e choro de Laura, levou-a para o terraço, com os brinquedos, separando-a do grupo até que ela se acalmasse.

Era frágil a interdição ao incesto naquela creche, à época: transposta ao campo educativo, essa lei proíbe preferências pessoais na sala de aula e na escola, exigindo sempre o bem coletivo como critério maior das ações (HEVÉLINE; ROBBES, 2009). Laura parecia simbolicamente usufruir de regalias junto ao diretor e à sua mãe, gozando de uma lei própria, em detrimento à lei 
geral, instituída para todas as crianças (dividir os brinquedos, não ir para outros espaços da creche sem a autorização da professora, fazer as atividades nos horários estabelecidos - banho, alimentação, hora de dormir, de brincar, de fazer as tarefas etc.). Laura representava um arranjo de forças em que o poder circulava de modo personalizado, avesso ao coletivo e ao institucional, por ser constituído prioritariamente de relações duais, nas quais o autointeresse é mais forte do que o bem-estar coletivo.

Os comportamentos de Laura, na perspectiva da PI, podem também ser interpretados como um pedido de limites à sua fantasia de onipotência, de uma contenção que os adultos, evidentemente, não conseguiam exercer, o que seria estabelecido através da instituição de lugares de fala e atividades que favorecessem o "encontro e a mediação intersubjetiva" (HEVÉLINE; ROBBES, 2009, p. 71) no espaço pedagógico. Milman (2005) ressalta: crianças que reagem assim não pedem apenas limites, mas também presença. Elas estão em busca do contato, em busca da oposição sensível e responsiva, proporcionada por uma companhia viva, por meio da qual possam redescobrir sua própria agressividade.

Sobre a agressividade, Winnicott (1990) defende que a educação das crianças não deveria objetivar controlar a agressividade, mas oferecer ambientes emocionais estáveis e confiáveis que possam garantir, a cada um, conhecer e tolerar como parte de si mesmo o conjunto total de sua agressividade (o ávido amor primitivo, a destrutividade, a capacidade de odiar etc.). A nosso ver, isso é o que propõe a PI, através da instituição de lugares de falas sob os dispositivos das leis, limites, linguagem e lugar (HEVÉLINE; ROBBES, 2009).

Em uma das reuniões de acompanhamento e escuta dos(as) educadores(as), o manejo do comportamento de Laura foi discutido, surgindo posições opostas sobre essas concessões à menina. A equipe de intervenção interpretou para as educadoras essa relação especial com o diretor, com base na hipótese de que Laura estaria pedindo limite aos adultos com sua conduta, justamente que os adultos fossem firmes e assegurassem seu lugar de criança, que sendo capazes de suportá-la e contê-la.

Para Winnicott (1990), uma criança normal não é aquela que se comporta de modo sempre desejável, mas aquela que usa de todos os meios possíveis para se impor, colocando à prova seu poder de desintegrar, destruir, assustar, cansar, manobrar, consumir e apropriar-se. Quando encontra um ambiente suficientemente forte e continente, capaz de conter suas tentativas de desorganizá-lo, ela tranquiliza-se e consegue se sentir livre e capaz de exercer sua criatividade, de brincar. Mas antes que isso aconteça, ela precisa se conscientizar das regras e fará tentativas para testá-las, especialmente quando tem alguma dúvida quanto à estabilidade do ambiente. 
A partir desses comportamentos de Laura, a equipe de intervenção definiu um protocolo comum, a fim de estabelecer um enquadre para a menina e, com isso, protegê-la - e, concomitantemente, salvaguardar as crianças e a própria equipe - de seus ataques. Essa lei grupal constitui um modo de defesa coletiva contra a ansiedade e, em geral, tranquiliza o grupo. Em situações de ataque, evitavam-se conversas paralelas e negara situação: levava-se o conflito para que o grupo pudesse, através da fala, explorar seus sentimentos e fantasias, garantindo-se posteriormente o enquadre. Se esse enquadre faltasse, algumas crianças contaminavam-se e passavam a atuar no grupo, repetindo os comportamentos desafiadores e agressivos de Laura.

Verificou-se que as intervenções feitas pela equipe na interação com as crianças liberavamnas para um brincar mais espontâneo e para a livre expressão de seus pensamentos e sentimentos, o que foi percebido em outra reunião com as crianças, na qual Laura disputava a atenção de uma extensionista que brincava com todos igualmente naquela hora, sem obter a exclusividade na interação. A menina passou, então, a gritar:

"Vem, tia!" “Todos os brinquedos são meus, meu padrinho me dá!”.

A extensionista, então, apresentou uma interpretação para a conduta de Laura:

"Por que será que você não está conseguindo brincar com todo mundo? Tem que ficar aqui, gritando, chamando a atenção, tomando os brinquedos dos teus coleguinhas? Você acha que se eu brincar com as outras crianças é porque eu não gosto de você? Quando a mamãe está cuidando dos bebês ela deixou de gostar de você? Não é nada disso: eu gosto de você, a mamãe também, então, não precisa ter medo, não precisa ter ciúmes. Além disso, é divertido também brincar com seus coleguinhas, não acha?".

Nesse momento uma das crianças se aproximou, pegou uma boneca e se sentou perto de Laura, que passou a brincar com ela.

Essa cena mostra o valor do brincar como atividade transformadora, mediadora, elaboradora das forças psíquicas infantis. Na perspectiva de Winnicott (1975), o brincar é constitutivo da cultura e um aspecto fundante da condição humana. $\mathrm{O}$ aspecto lúdico permite que a criança, ou mesmo o adulto, possa construir um conhecimento de si e sua rede de relações sociais, uma vez que o brincar acontece em um espaço potencial.

O brincar, na infância, também mostra uma possibilidade de acesso ao inconsciente, por meio do faz-de-conta, que opera como um estímulo de elaboração da fase de transição das fantasias do mundo subjetivo para a realidade do mundo objetivo. Constitui-se, portanto, num dos primeiros ensaios do processo de separação do bebê de sua mãe, auxiliando na elaboração das fantasias inconscientes da criança. 
Brincar e tornar-se cultural são processos convergentes. No que se refere à "experiência cultural", Winnicott (1975) afirma que é no espaço potencial que acontece o jogo criativo dos primórdios da existência, oficializa-se a experiência da vida criativa, aperfeiçoando-se o uso dos símbolos na mediação da linguagem, seja na sua relação com o mundo interno e ou nas relações com o ambiente e demais aspectos constitutivos da cultura afirmando que:

O espaço potencial entre o bebê e a mãe, entre a criança e a família, entre os indivíduos e a sociedade ou o mundo, depende da experiência que conduz à confiança. Pode ser visto como sagrado para o indivíduo, porque é aí que este experimenta o viver criativo. (WINNICOTT, 1975, p. 142).

Conseguir brincar, como efeito de um enquadre em que o incesto foi interditado pela equipe extensionista (tanto diretamente, para Laura, quanto indiretamente, no acompanhamento dos profissionais da creche), foi extremamente valioso para Laura. Brincando com duas ou mais outras crianças, a menina conseguiu desenvolver um padrão que, por sua simplicidade e recorrência, muitas vezes não chama a atenção para o que se lhe subjaz: a formação da capacidade de preocuparse com o outro, de se interessar por (e se envolver com) ele. Ora, esse é um dos fundamentos subjetivos da cultura de paz.

Tanto isso é verdadeiro que os conflitos com Laura reduziram-se. A equipe percebeu que a menina, desde então, ficou mais tranquila no grupo, conseguindo frequentemente brincar com outras crianças e aceitando regras, embora os extensionistas se mantivessem atentos aos movimentos de Laura que fossem agressivos ou transgressores, já que uma retomada do padrão chantagista, tantas vezes reforçado, sempre foi considerada: a proximidade entre pai, mãe e padrinho e as funções institucionais (inspetor, cuidadora de bebês, diretor, respectivamente) era capaz de renovar a confusão que antes alimentava o "incesto", ou seja, a criação de prerrogativas indevidas para Laura.

Em uma das atividades lúdicas, ela pediu para "brincar de psicóliga", imitando as extensionistas que entraram no jogo e se revezavam com outras crianças nesse papel: Laura conseguiu, interagindo com outras crianças, assumir o lugar de quem, no passado, interditou seus desejos incestuosos e forneceu limites para seus impulsos agressivos - divertindo-se nesse jogo de troca de papéis.

Ao invés de querer na realidade tomar o lugar de um adulto, Laura pôde brincar, fazer de conta que era uma "psicóliga", passando a simbolizar algo que na sua fantasia teria peso de realidade (psíquica), mas que, na realidade material, seria impossível para a criança suportar 
naquele momento, por ser o lugar do adulto: na brincadeira ela conseguiu expressar seu desejo, sem na realidade material concretizá-lo.

Pensando a situação vivida por Laura, a equipe extensionista também se defrontou com seu desejo de onipotência e as angústias relativas ao controle desse impulso, também associado à violência (já que esta forma de resolução de conflitos baseia-se na crença de que a diferença de forças é natural e legitima a imposição do mais forte sobre o mais fraco). Como ocorre na relação entre adultos e crianças, estas últimas tornam-se porta-vozes dos desejos dos adultos, sendo seus sintomas fundados na intensificação de fantasias arcaicas dos adultos.

Diante disso, a função primordial dos extensionistas foi a de proteger o grupo da fantasia coletiva de destruição no conflito, para compreender, elucidar e interpretar os fenômenos grupais. Nesse sentido, foi vital que os extensionistas tenham se mantido atentos a sua própria contratransferência.

A contratransferência pode ser compreendida como o "conjunto das reações inconscientes do analista à pessoa do analisando e, mais particularmente a transferência deste" (LAPLANCHE; PONTALIS, 1995, p. 102). Transposto para o meio escolar, esse processo sugere que os adultos e profissionais, na escola, devem constantemente examinar suas subjetividades, individual e grupalmente, a fim de checar se suas fantasias inconscientes também afetam negativamente o processo de resolução pacífica dos conflitos.

Partindo da ideia de que existem fenômenos inconscientes que agem na relação de um adulto e uma criança, capazes de interferir no seu processo de desenvolvimento cognitivo, afetivo, social e psíquico (WINNICOTT, 2000; MOREIRA, 2005), a recíproca também é verdadeira: não obstante estarem menos suscetíveis à influência consciente do que as crianças, os adultos também podem deixar-se marcar psicodinamicamente pelos processos que viabilizam a aprendizagem. Do ponto de vista psicanalítico, não é possível aprender sem se ver às voltas com desejos e processos inconscientes, que repercutem na afetividade, na cognição e na motivação para aprender (KUPFER, 1989; ANDRADE, 2009). Isso é ainda mais verdadeiro no que toca à escola, como explica a PI (ANDRADE; CARVALHO, 2009).

Os profissionais da creche, nos encontros quinzenais com os extensionistas, pareciam mais à vontade para trazer situações de indisciplina das crianças: em especial, a educadora da sala de Laura revelava-se mais ativa quanto à aplicação das regras e mais atenta às demandas das crianças. Dito de outra forma, como entende a PI, as leis que servem para todos e são inegociáveis, além de não poderem ser questionadas, contribuem para que todos os atores do campo educativo ocupem seus lugares simbólicos. 
Como demonstra a história dos conflitos relacionais provocados e vividos por Laura, o enquadre é condição para que uma cultura de paz constitua-se desde a primeira infância, nas instituições de educação infantil. É possível, desde muito cedo, promover essa cultura, sem que não sejam ainda capazes as crianças de entender abstratamente as leis, as normas e os lugares defendidos pela PI.

Por se constituir um sistema operatório provido de uma coerência interna, o enquadre, por si só é capaz de provocar modificações na dinâmica do grupo. Isso permite que haja um limite e um espaço onde as manifestações de conflitos e fantasmas subjacentes, tanto no que se refere ao nível individual quanto grupal, possam vir à tona e ser elaborados. Neste sentido, com os dispositivos que criou e adaptou, se observa a contribuição da PI para a constituição de uma cultura de paz.

\section{Rumo a uma cultura de paz: considerações finais}

A história que envolveu Laura, suas educadoras, familiares e extensionistas, em sua creche, evidenciou que a ausência de leis claras e inegociáveis mantinha o círculo vicioso de relações interpessoais pautadas na atuação dos desejos incestuosos e dos impulsos agressivos. Por outro lado, também mostrou, aos poucos, com a criação e manutenção de alguns limites - instituindo lugares simbólicos onde a linguagem estava implicada e estruturava as relações interpessoais, favorecendo a descarga das tensões e dos conflitos intersubjetivos por vias não violentas, como a fala ou o brincar - são importantes para transformar, por sublimação e identificação, tais desejos e impulsos.

A história daquela menina em sua creche evidenciou o quanto a apresentação de limites à agressividade infantil é importante para permitir a convivência, a aprendizagem de valores voltados para a paz e a identificação com os princípios da sociabilidade. Esses limites e suas potencialidades criadoras são bem dimensionados, no campo pedagógico, pela Pedagogia Institucional, cujos dispositivos serviram aqui de referência teórica para ajudar a ler processos que se deram ao longo de um ano de atividades na creche, envolvendo aquela menina.

O suporte teórico winnicottiano traz, a nosso ver, lentes diferenciadas para essa leitura, evidenciando o potencial criativo da agressividade - que, nesse sentido, de modo distinto à perspectiva francesa, é positivada. Com esse outro ponto de vista teórico, não só a agressividade e a violência são admitidas como possibilidades permanentes, mas, no caso da interpretação winnicottiana, são integradas como sinais de vida e de esperança - duas condições para as quais 
toda pedagogia trabalha, contribuindo, manifesta ou implicitamente, para o desenvolvimento emocional das crianças e adolescentes.

Se, como o caso evidenciou, no início da intervenção, muitas das relações entre adultos e crianças eram funcionais e preenchidas por tarefas, sem tempo nem lugar para que se desenvolvesse uma convivência mais atenta aos afetos, pouco a pouco a atenção a tais práticas e à afetividade implícita nelas evidenciou alternativas e necessidades não atendidas. $\mathrm{O}$ enquadre, oferecendo limites, pôde ser sustentado graças à convicção - comum à PI - de que somente um espaço continente pode fazer-se um espaço potencial, capaz de produzir criação e, consequentemente, aprendizagens.

Nesse sentido, finalmente, entendemos que conflitos relacionais na escola, quando bem geridos, acompanhando princípios e instituições explicitados pela PI, podem favorecer o crescimento emocional e a aprendizagem em direção à convivência cidadã, capacidade indissociável à construção de uma cultura de paz na escola.

Além da clareza sobre as ações e valores que pautam o cotidiano pacífico (respeitar a vida, rejeitar a violência, ser generoso, ouvir para compreender, preservar o planeta e redescobrir a solidariedade), para alcançar essas práticas de convivência pacífica na escola, são necessárias técnicas e estratégias que considerem a subjetividade dos participantes da cena pedagógica, como é o caso da Pedagogia Institucional.

Aos adultos encarregados, como profissionais, do trabalho de manejo pedagógico das tensões de convivência nesse cenário, exige-se disponibilidade interna e afetiva para identificarem, pensarem e agirem sobre essas situações de conflitos relacionais experimentados em sala de aula e no espaço escolar.

Para direcionar o alunado no sentido da formação da capacidade de viver em sociedade, a capacidade de preocupar-se com o outro precisa ser desenvolvida, o que só acontece em ambientes nos quais a separação entre impulsos e sua manifestação nas relações sociais esteja garantida.

\section{Referências bibliográficas}

ABRAMOVAY, M.; RUA, M. G. (Org.) Violências nas Escolas - Brasília: UNESCO, 2002.

ABRAMOVAY, M. (Coord.). Escolas inovadoras: experiências bem-sucedidas em escolas públicas - Brasília: UNESCO, Ministério da Educação, 2004.

ANDRADE, F. C. B. Tornar-se uma lição permanente: psicodinâmica da competência interrelacionaldo(a) educador(a) na gestão de conflitos e na prevenção da violência na escola. 2007. 220p. Tese (Doutorado em Educação) - Universidade Federal da Paraíba, João Pessoa, 2007. 
Do saber desejar ao desejar saber: contribuições da psicanálise à educação escolar. In: SALES, V. F; SILVA, M. S. M. M.; BATISTA, J. B. V. (Orgs.). Psicologia na Educação - Um referencial para professores. $2^{\mathrm{a} e d . J o a ̃ o ~ P e s s o a-P B: ~ E d i t o r a ~ U n i v e r s i t a ́ r i a-U F P B, ~ 2005, ~ v . ~ u ́ n i c o, ~ p . ~}$ 79-110.

ANDRADE, F. C. B.; CARVALHO, M. E. P. (Orgs.). Instituir para ensinar e aprender: introdução à Pedagogia Institucional. João Pessoa: Editora da UFPB, 2009.

COLOMBIER. C.; MANGEL, G.; PERDRIAULT, M. A violência na escola. São Paulo: Summus, 1989.

DEBARBIEUX, E.; BLAYA, C. (Orgs.)Violências nas escolas e políticas públicas. - Brasília: UNESCO, 2002.

DELORS, J. et al.Educação: um tesouro a descobrir. - 10 ed. - São Paulo: Cortez; Brasília, DF: MEC: UNESCO, 2006.

DISKIN, L; ROIZMAN, L.G. Paz, como se faz?Semeando cultura de paz nas escolas - Brasília: Governo do Estado de Sergipe, UNESCO, Associação Palas Athena, 2002.

GALLO, S. Transversalidade e educação: pensando uma educação não disciplinar. In: ALVES, N.; LEITE, R. (Orgs.). O sentido da Escola. 2 ed. Rio de Janeiro: DP\&A, 2000.

HÉVELINE, E.; ROBBES, B. Questions d'ecole: démarrer une classe em pédagogieinstitutionnelle. Paris: HATIER, 2000.

HÉVELINE, E.; ROBBES, B.. Praticando a Pedagogia Institucional: o que é a pedagogia institucional. In: ANDRADE, F. C. B.; CARVALHO, M. E. P. (Orgs.). Instituir para ensinar e aprender: introdução à Pedagogia Institucional. João Pessoa: Editora da UFPB, 2009, p.19-108.

JIMÉNEZ, M. C. Del conflito a la cultura de paz: implicaciones. Revista Iberoamericana de Educación. $\mathrm{N}^{\mathrm{o}} 44$ - 25 de noviembre de 2007. Ed. Organización de Estados Iberoamericanos para laEducación, laCiencia y la Cultura.

KUPFER, M.C. Freud e a educação: o mestre do possível. São Paulo: Scipine, 1989.

LAPLANCHE, J.; PONTALIS, J-B. Vocabulário da Psicanálise. São Paulo: Martins Fontes, 1995.

MARCHESI, A. O bem-estar dos professores: competências, emoções e valores. Trad. Naila Tosca de Freitas - Porto Alegre: Artmed, 2008.

MILMAN, L. Casa da Árvore: a ética de Françoise Dolto nas favelas cariocas. 2005. Disponível em: <http://www.editoraescuta.com.br/pulsional/181_06.pdf> Acessado em: 25 de maio de 2016.

MOREIRA, A.F.B. Currículo e Estudos Culturais: tensões e desafios em torno das identidades. In: SILVEIRA, R.M.H. (Org.). Cultura, poder e educação:um debate sobre estudos culturais em educação. - Canoas: Ed. ULBRA, 2005.

OLIVEIRA, M. M. Como fazer Pesquisa Qualitativa. Recife: Bagaço, 2005. 
OZÓRIO, L. C.; ZIMERMAN, D. E. Como trabalhamos com grupos. Porto Alegre: Artes Médicas, 2001.

PAIN, J. L'École et sesViolences. Paris: Economica/Antrophos, 2006.

A Pedagogia Institucional ontem e hoje. In: ANDRADE, F. C. B.; CARVALHO, M. E. P. (Orgs.). Instituir para ensinar e aprender: introdução à pedagogia institucional. João Pessoa: Ed. Universitária da UFPB, 2009.

SAMPAIO, R.M.W. Freinet: evolução histórica e atualidades. São Paulo: Scipione, 2007.

WINNICOTT, D. W. O Brincar e a Realidade. Rio de Janeiro: Imago, 1975.

O ambiente e os processos de maturação: estudos sobre a teoria do desenvolvimento emocional. Porto Alegre: Artmed, 1983.

Cartas 1 - 126. In: WINNICOTT, D.W.O gesto espontâneo. Rio de Janeiro: Martins Fontes, 1990. p. 1-171.

Da Pediatria à Psicanálise: obras escolhidas. Rio de Janeiro: Imago, 2000.

. Privação e delinquência. 4 ed.-São Paulo: Martins Fontes, 2005.

. A criança e o seu mundo. 6 ed. Rio de Janeiro: LTC, 2008.

Recebido em: 01.06.2016

Aceito em: 21.07.2017 